\title{
Baclofen for maintenance treatment of opioid dependence: A randomized double-blind placebo-controlled clinical trial [ISRCTN32I 2 I58I]
}

\author{
Seyed Mohammad Assadi*, Reza Radgoodarzi and Seyed Ali Ahmadi-Abhari
}

Address: Psychiatric Research Center and Department of Psychiatry, Roozbeh Psychiatric Hospital, Tehran University of Medical Sciences, South Kargar Avenue, Tehran 13337, Iran

Email: Seyed Mohammad Assadi* - assadism@sina.tums.ac.ir; Reza Radgoodarzi - rezaradus@yahoo.com; Seyed Ali Ahmadi-

Abhari - ahmadiab@sina.tums.ac.ir

* Corresponding author

Published: 18 November 2003

BMC Psychiatry 2003, 3:16
Received: 17 August 2003

Accepted: 18 November 2003

This article is available from: http://www.biomedcentral.com/l47I-244X/3/16

(c) 2003 Assadi et al; licensee BioMed Central Ltd. This is an Open Access article: verbatim copying and redistribution of this article are permitted in all media for any purpose, provided this notice is preserved along with the article's original URL.

\begin{abstract}
Background: Results of preclinical studies suggest that the $G A B A_{B}$ receptor agonist baclofen may be useful in treatment of opioid dependence. This study was aimed at assessing the possible efficacy of baclofen for maintenance treatment of opioid dependence.
\end{abstract}

Methods: A total of 40 opioid-dependent patients were detoxified and randomly assigned to receive baclofen $(60 \mathrm{mg} /$ day) or placebo in a 12 -week, double blind, parallel-group trial. Primary outcome measure was retention in treatment. Secondary outcome measures included opioids and alcohol use according to urinalysis and self-report ratings, intensity of opioid craving assessed with a visual analogue scale, opioid withdrawal symptoms as measured by the Short Opiate Withdrawal Scale and depression scores on the Hamilton inventory.

Results: Treatment retention was significantly higher in the baclofen group. Baclofen also showed a significant superiority over placebo in terms of opiate withdrawal syndrome and depressive symptoms. Non-significant, but generally favorable responses were seen in the baclofen group with other outcome measures including intensity of opioid craving and self-reported opioid and alcohol use. However, no significant difference was seen in the rates of opioid-positive urine tests. Additionally, the drug side effects of the two groups were not significantly different.

Conclusion: The results support further study of baclofen in the maintenance treatment of opioid dependence.

\section{Background}

Recent preclinical studies offer support for the idea that a number of GABAergic drugs, particularly baclofen, may help promote abstinence from a variety of drugs of abuse [1]. For example, many studies with rats have shown that the $\mathrm{GABA}_{\mathrm{B}}$ receptor agonist baclofen suppresses selfadministration of cocaine, ethanol, nicotine and methamphetamine [2-9]. Moreover, one study has reported that baclofen reduces self-administration of heroin in rats [10] and two other studies have shown that baclofen reduces opioid withdrawal signs in morphine-dependent animals [11,12].

Taken overall, these studies indicate that baclofen may be effective in attenuating drug-associated positive and negative reinforcements. In positive reinforcement, a rewarding 


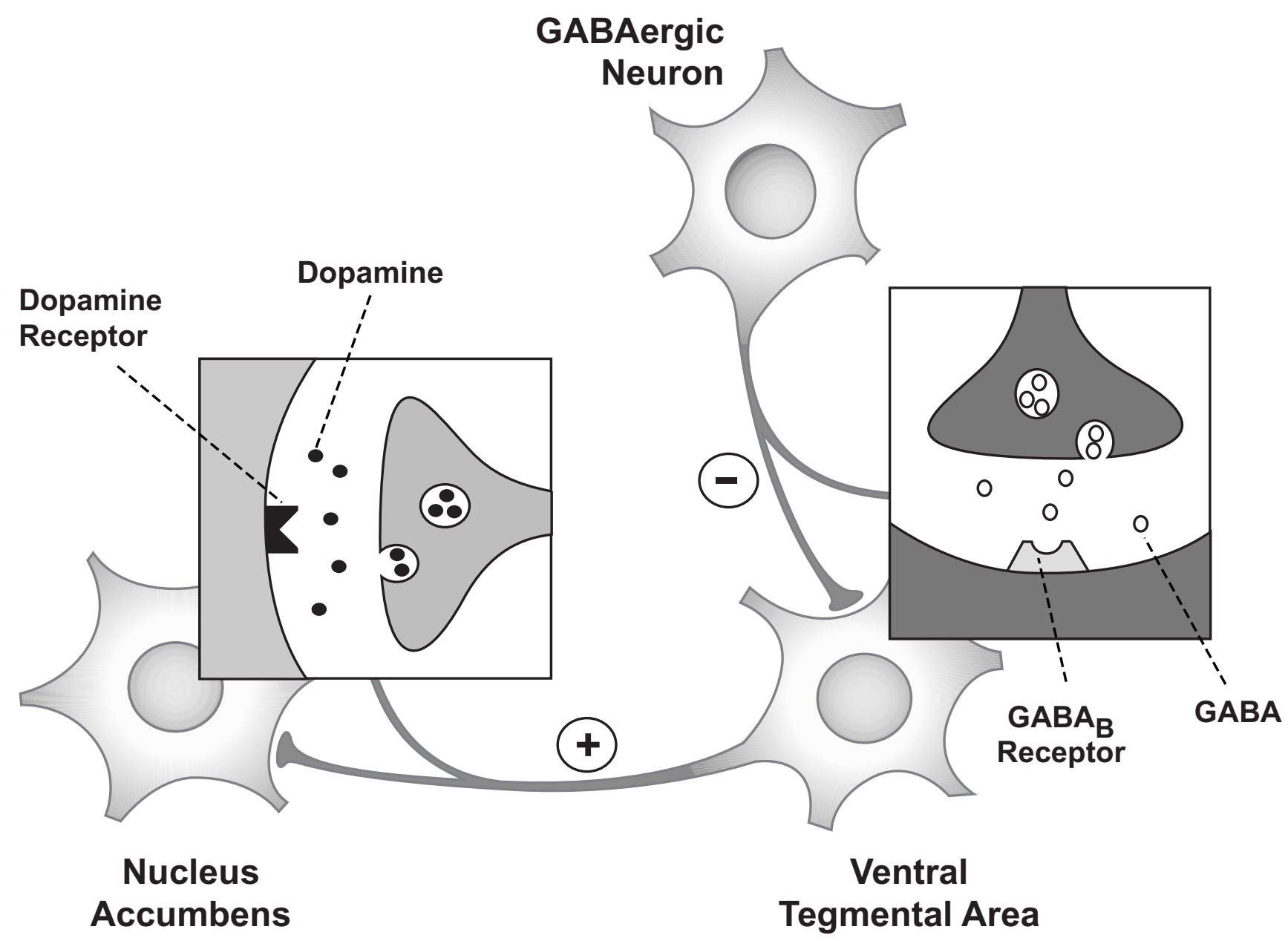

Figure I

The primary portion of brain reward circuitry appears to be a subset of dopaminergic projections originating in the ventral tegmental area (VTA) and terminating in the nucleus accumbens (NA). VTA is modulated by GABAergic inputs. GABA ${ }_{B}$ receptors inhibit VTA cell bodies, i.e., when stimulated, hyperpolarize the membrane potential and decrease firing rates of VTA neurons.

stimulus (e.g., drug-induced euphoria) directly increases the probability of a response (e.g., continued drug use). Neuroanatomically, the mesolimbic dopamine system has been linked to the positive reinforcing effect of cocaine, nicotine, heroin and ethanol. The primary portion of this system appears to be a subset of dopaminergic projections originating in the ventral tegmental area (VTA) and terminating in the nucleus accumbens (NA) (Fig. 1). Drugs of abuse increase the firing rates of this projection and consequently, elevate extracellular dopamine levels in NA $[13,14]$. On the other hand, VTA is modulated by GABAergic inputs $[15,16]$. $\mathrm{GABA}_{\mathrm{B}}$ receptors are highly distributed in this area and inhibit VTA cell bodies, i.e., when stimulated, hyperpolarize the membrane potential and decrease firing rates of VTA neurons [17]. Xi and Stein [10] have shown that systemic administration of baclofen dose-dependently decreases heroin-induced dopamine release in the NA and reduces the positive reinforcing properties of heroin. One the other hand, in negative reinforcement, the incentive for drug use is relief of a painful or unpleasant state (i.e., negative affective symptoms of withdrawal such as dysphoria, depression, irritability and anxiety) [40]. Preclinical evidences suggest that baclofen may reduce opioid withdrawal symptoms $[11,12]$. Therefore, baclofen could be also useful in the management of opioid dependence by attenuating withdrawal symptoms and consequently, by reducing negative reinforcing properties of opioids.

A few clinical studies have been conducted with baclofen in cocaine, ethanol and nicotine users [1,18-20,38,39] and one study has compared the efficacy of baclofen 
versus clonidine in acute detoxification of opioid dependents [21]. However, while preclinical studies support the idea that baclofen may help maintaining abstinence from opioids via reducing both the positive reinforcing (reward) properties $[10,22]$ and negative reinforcement (withdrawal) of opioids $[11,12]$; to the best of our knowledge, there is no reported clinical trial that has evaluated the efficacy of baclofen in maintenance therapy of opioid dependence.

We conducted a randomized, double blind, placebo-controlled, 12-week clinical trial to evaluate the possible benefit of baclofen in the maintenance treatment of opioid addicts. We primarily hypothesized that baclofen is superior to placebo in terms of retaining opioid addicts in the maintenance treatment.

\section{Methods \\ Subjects and setting}

Subjects were eligible for the study if they met DSM-IV criteria for opioid dependence [23], were detoxified at our addiction clinic under the protocol discussed below, were between 18 and 60 years of age, and gave written informed consent for participation in the study. Subjects were disqualified if they were pregnant or lactating; had clinically serious unstable medical illness; were receiving other medications; had a history of psychosis, mania or severe major depression; reported concurrent dependency to alcohol, cocaine or hallucinogens; had a history of antisocial personality; or were mentally retarded.

Subjects were recruited from individuals seeking opioid detoxification at the addiction clinic of Roozbeh Psychiatric Hospital (the major psychiatric hospital affiliated with Tehran University of Medical Sciences, Iran). Patients could withdraw their participation at any time and transfer to a conventional treatment. Those completing the trial were also guaranteed transfer to a conventional treatment (including naltrexone, individual counseling, and weekly group psychotherapy with a focus on relapse prevention). The study was conducted in accordance with the Declaration of Helsinki and subsequent revisions and was approved by the ethical committee at Tehran University of Medical Sciences and by the research steering committee at the psychiatric department of Tehran University of Medical Sciences. Patient enrolment began in November 2001 and was completed in November 2002.

\section{Detoxification phase}

Once informed consent for detoxification was obtained, subjects were detoxified in an outpatient setting with the same treatment protocol lasting 2 weeks, including therapy with clonidine, clonazepam and thioridazine. In the last half of the detoxification period, all medications were tapered and finally discontinued except for thioridazine, which was permitted throughout the study in doses discussed below. At the end of the detoxification period, a naloxone challenge test (subcutaneous injection of 0.8 mg of naloxone) was performed; patients with negative results were considered successfully detoxified and were eligible for the initiation of maintenance treatment.

\section{Maintenance treatment phase}

After giving written informed consent, detoxified subjects entered a parallel group, randomized, double blind, fixedschedule, 12-week clinical trial. The clinical trial was conducted in an outpatient setting. Subjects were randomly assigned to treatment with baclofen or placebo, using a computer-generated list of random numbers. A research pharmacist prepared and dispensed all medications and was the only person with knowledge of drug assignment. The rater and patients remained blind to the treatment up to the end of the study.

The initial daily dose of baclofen was $10 \mathrm{mg}$, increased to $60 \mathrm{mg}$ ( $20 \mathrm{mg}$ t.i.d.) over five days. The dose of $60 \mathrm{mg}$ was chosen in concordance with a clinical study that had evaluated baclofen for management of cocaine craving [18]. In order to preserve the double blind condition, baclofen and placebo were dispensed in identical-appearing tablets and all patients received 6 tablets daily in 3 divided doses. Both groups received thioridazine $25-100 \mathrm{mg}$ if needed at night for management of insomnia. No other psychotropic medication was prescribed. Subjects did not receive any concomitant psychological treatment or psychosocial support.

Patients were required to attend the clinic weekly to receive their medication, complete measures, and provide urine samples. The subjects who failed to attend one appointment were encouraged by phone call to continue treatment and were not excluded from the study for illicit drug use. Patients were discharged from the study if they 1) missed two consecutive appointments or 2) used opioids in doses as high as the amount used prior to the detoxification for more than five consecutive days that led to the necessity of their detoxification again. In these cases, they were discharged from the study and referred for the conventional treatments. Intermittent attendance was tolerated.

\section{Assessments}

Patients were evaluated at the study entry with a psychiatric history and semistructured interview that included a DSM-IV diagnostic checklist. A medical history and physical examination were also performed. Moreover, demographic characteristics and other variables that could influence the outcomes of maintenance therapy [24-26] were recorded. 
Primary outcome variable was retention in treatment, which was defined as the number of weeks that patients remained in the study before being discharged. In addition, patients were examined weekly to determine use of opioids, alcohol and other substances; opioid withdrawal syndrome; and intensity of opioid craving. Substance use was assessed by urinalysis and self-reports. Urine samples were collected weekly and Thin Layer Chromatography (TLC) was used to determine the presence of opiates. Rates of opioid-positive urine tests were calculated for each patient by dividing the number of opioid-positive and missing urine specimens by the number of urine samples stipulated for the retention period. Self-report ratings of drug and alcohol use were collected by an inventory that was developed according to the reported items of the Weekly Drug Use Inventory [27]. Subject were asked to report the number of days during the past week that they used opioids, alcohol or other illicit drugs; the routes of administration used for each drugs; and the average amount used each day in grams or rials (the unit of money in Iran). Opioid craving was assessed with a visual analogue scale (VAS). Patients expressed their level of craving in the preceding week by making a mark on a $10 \mathrm{~cm}$ line, ranging from no craving at one end to the most intensive craving ever experienced at the other end. Opioid withdrawal symptoms were assessed with the Short Opiate Withdrawal Scale (SOWS) [28]. Every two weeks, depression was assessed with the Hamilton Depression Rating Scale (HAM-D) [29] and adverse events were assessed systematically with a score sheet designed for the present study. A third year resident of psychiatry (R. R.) who was trained in the usage of the scales performed all clinical research measurements.

\section{Statistical analysis}

Data analyses were conducted on the enrolled subjects who met eligibility criteria for participation in the trial (intention-to-treat analysis). Patients were compared for socio-demographic variables by means of the chi-square for categorical variables, and the $t$-test for continuous variables. Associations between these variables and the primary outcome measure (retention in treatment) were analyzed with the Cox's regression model. Retention rates were assessed by the Kaplan-Meier method [30]. KaplanMeier curves were compared using the log-rank test $[31,32]$. Patients who completed the 12-week trial were regarded as censored observation. Data on the SOWS, HAM-D, opioid craving, and self-reports of opioids and alcohol use were analyzed with repeated measures analysis of variance (ANOVA), using treatment group as the between-subjects factor and time as the within-subjects variable. Missing data were replaced using a last-observation-carried-forward approach. Other outcome measures were assessed by the chi-square and t-tests, and MannWhitney $U$-tests. The chi-square test was used to verify dif-

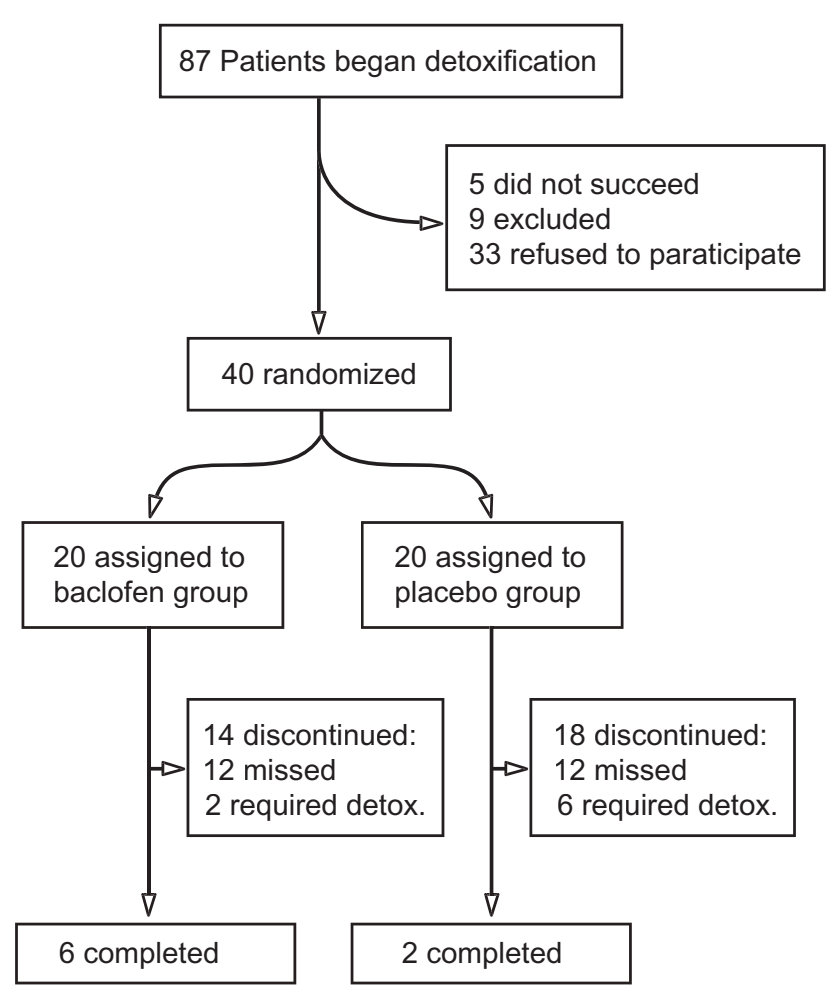

Figure 2

Trial profile

ferences in frequencies. Mean value comparisons were conducted after verifying the distribution of data; parametrically, using the unpaired $t$-test, or using the MannWhitney $U$-test for non-Gaussian distributions.

Frequencies were assessed in absolute and relative terms and data on interval scale levels were described using mean values and standard deviation. All statistical tests were two-sided, and were considered significant at $P<$ 0.05 .

\section{Results \\ Sample characteristics}

Eighty-seven patients initiated the detoxification but only 40 of them began the maintenance treatment. Reasons for withdrawal of participation were premature termination of detoxification (5), diagnosis of interfering medical or psychiatric illnesses (9) and consent withdrawal (33) (Fig. 2).

Characteristics of study sample are shown in Table 1 . The two treatment groups did not differ significantly in the majority of the socio-demographic and clinical variables investigated at the baseline. The only significant 
Table I: Baseline characteristics of 40 patients with DSM-IV opioid dependence randomly assigned to receive baclofen or placebo.

\begin{tabular}{|c|c|c|c|c|}
\hline Variable & Baclofen & $(\mathbf{N}=\mathbf{2 0})$ & Placebo & $(\mathbf{N}=\mathbf{2 0})$ \\
\hline & Mean & $S D$ & Mean & $S D$ \\
\hline Age (years) & 35.1 & 10.9 & 31.8 & 6.5 \\
\hline Age of onset of opioid use & 23.2 & 6.2 & 21.0 & 4.9 \\
\hline Duration of opioid use (years) & 8.8 & 6.2 & 7.0 & 4.9 \\
\hline Number of previous abstinences & 3.7 & 2.2 & 2.2 & 1.9 \\
\hline Duration of the longest previous abstinence (months) & 4.4 & 5.5 & 4.1 & 5.6 \\
\hline \multirow[t]{2}{*}{ Income per month (Rials/10000) } & 81.7 & 69.3 & 99.5 & 103.7 \\
\hline & $\mathbf{N}$ & $\%$ & $\mathbf{N}$ & $\%$ \\
\hline Sex (male) & 20 & 100 & 20 & 100 \\
\hline Married & 14 & 70 & 10 & 50 \\
\hline College education & 2 & 10 & 2 & 10 \\
\hline Employed & 14 & 70 & 10 & 50 \\
\hline Substance use in patient's family & 13 & 65 & 17 & 85 \\
\hline \multicolumn{5}{|l|}{ Type of opioid } \\
\hline Heroin & 7 & 35 & 6 & 30 \\
\hline Opium & 13 & 65 & 14 & 70 \\
\hline \multicolumn{5}{|l|}{ Route of opioid use } \\
\hline Inhalation or ingestion & 12 & 60 & 10 & 50 \\
\hline Injection or multiple routes & 8 & 40 & 10 & 50 \\
\hline Psychiatric illness & 5 & 25 & 8 & 40 \\
\hline Medical illness & I & 5 & 0 & 0 \\
\hline
\end{tabular}

difference observed was in the number of previous abstinences $(t=2.32, P=0.02)$. Since an association between this variable and the primary outcome measure under investigation (retention in treatment) was not found (Wald statistics $=0.57, P=0.45$ ), it was not included as a covariate in the following analyses.

\section{Retention in treatment}

Survival curves for the two groups are shown in Fig. 3. Retention in treatment was significantly better in the baclofen group $(\log -r a n k=5.80, P=0.01)$. Subjects treated with baclofen were retained in the study for longer (55.3 \pm 21.9 days) than the placebo-treated subjects (36.4 \pm 22.1 days $)(t=2.72, P=0.01)$. Mann-Whitney $U$-test also showed that patients from the baclofen group completed significantly more weeks $(U=99.50, P=0.00)$.

The study was completed by $30 \%$ of patients from the baclofen group versus $10 \%$ from the placebo group. Reasons for dropping out from the trial differed in the two groups. In the group that took baclofen, the treatment of 12 patients $(60 \%)$ was interrupted due to missing of $\geq 2$ consecutive appointments and in two others $(10 \%)$, interruption was due to persistent use of opioids which required detoxification. In the group that took placebo, the treatment of 12 patients $(60 \%)$ was similarly interrupted due to missing of $\geq 2$ consecutive appointments; however, 6 patients (30\%) dropped out due to persistent use of opioids which required detoxification. No patients in neither of the treatment groups reported adverse effects that required dose reduction or termination from the study; moreover, no statistically significant differences were found between the two groups regarding the reported adverse effects (Mann-Whitney $U=179, P=$ $0.57)$.

\section{Effects on substance use}

The rates of opioid-positive urine samples did not differ significantly between the two groups: $76.9 \% \pm 24.3 \%$ and $75.8 \% \pm 24.3 \%$ for patients treated with baclofen and placebo, respectively (Mann-Whitney $U=191.5, P=0.82$ ). Overall, there was a significant increase in the selfreported days per week using opioids over time $(F=$ $13.54, P=0.00)$ with linear trend $(F=20.00, P=0.00)$ but no significant difference between the two groups $(F=$ $1.63, P=0.20)$ and no significant interaction between treatment group and time $(F=1.21, \mathrm{P}=0.27)$ were seen. However, as shown in Fig. 4 , the baclofen group exhibited a trend toward gentler slope of increase and the two groups appeared to diverge over weeks. Nearly similar pattern was observed with self-reports of alcohol consumption. There was a significant main effect of time $(F=$ $1.95, P=0.03$ ) but both the main effect of treatment and the interaction of treatment and time were not significant ( $F=0.85, P=0.36$ and $F=0.39, P=0.95$; respectively).

\section{Other outcomes}

Overall, there was no significant difference between the two groups on opioid craving scores. Although the main effect of time was significant $(F=4.68, P=0.00)$, there 


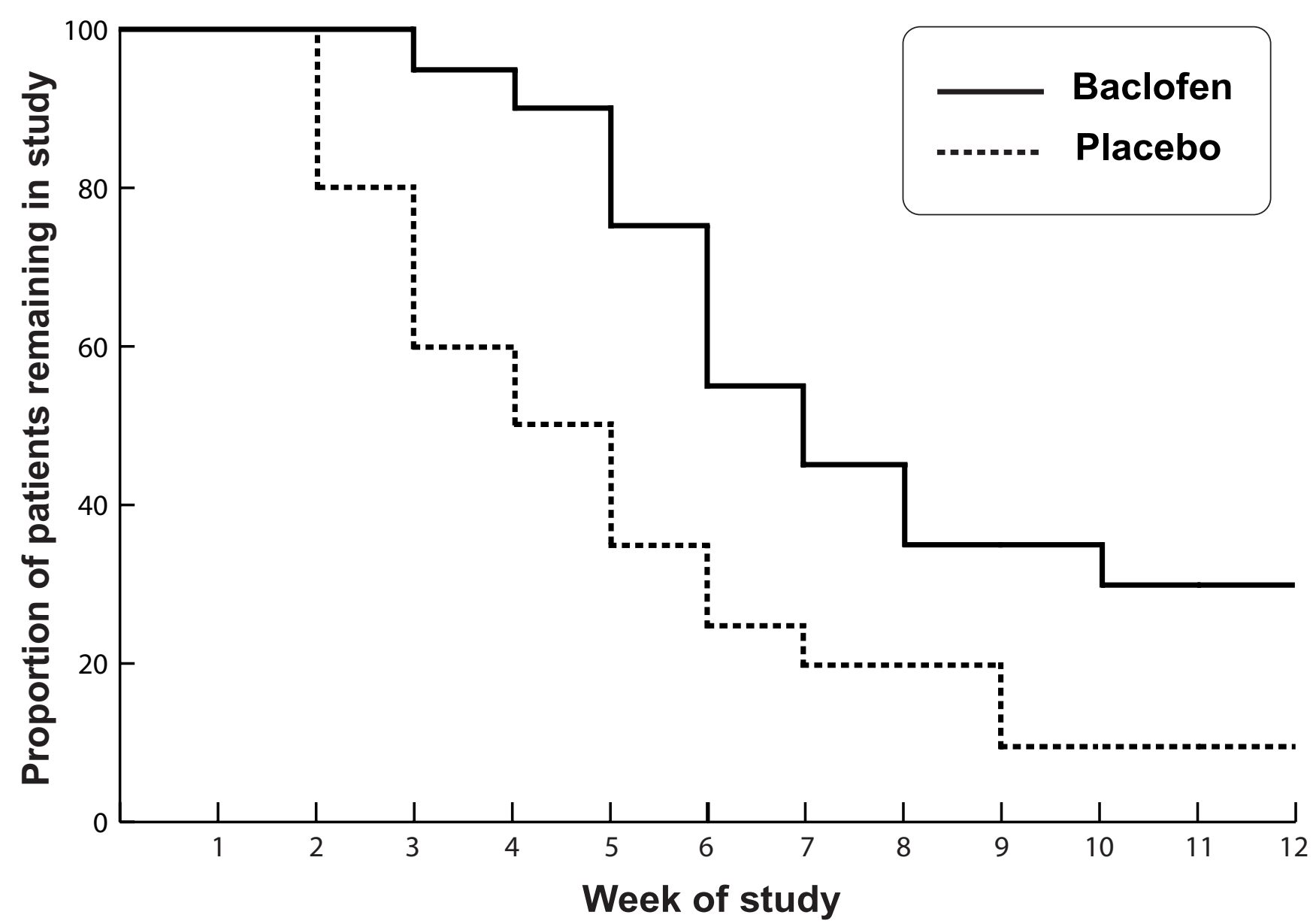

Figure 3

Percentage of patients in each group who remained in treatment.

was no significant main effect of treatment or treatmentby-time interaction $(F=1.45, P=0.23$ and $F=0.64, P=$ 0.78 ; respectively). Yet, the VAS scores were generally lower in the baclofen group. Average scores on the VAS were $37.1 \pm 20.2$ for the baclofen group compared to 43.7 \pm 25.3 for the placebo group.

Changes in intensity of the SOWS scores over time during treatment with baclofen and placebo are shown in Fig. 5. The repeated measure ANOVA showed that decrease in the SOWS scores was significantly more pronounce in the baclofen group. There was a significant main effect of treatment $(F=9.45, P=0.00)$ and time $(F=26.10, P=$ $0.00)$ but no significant interaction between time and treatment was noted $(F=1.42, P=0.16)$.

Baclofen was also statistically superior to placebo on the HAM-D ratings (Fig. 6). There was a significant main effect of treatment $(F=4.66, P=0.03)$ and the main effect of time and treatment-by-time interaction were also significant $(F=15.90, P=0.00$ and $F=4.45, P=0.00$; respectively).

\section{Discussion}

This report provides data from what we believe is the first randomized, double blind, placebo-controlled clinical trial evaluating the efficacy of baclofen in the maintenance treatment of opioid dependence. Results showed that baclofen is significantly superior to placebo in terms of retention in treatment, opiate withdrawal syndrome, and depressive symptoms. Additionally, baclofen showed generally favorable responses along other outcome measures including opioid craving and self-reported opioid and alcohol use; however, the differences were not significant. This study failed to show any effects for baclofen over placebo with regard to urinalysis. The failure to find 


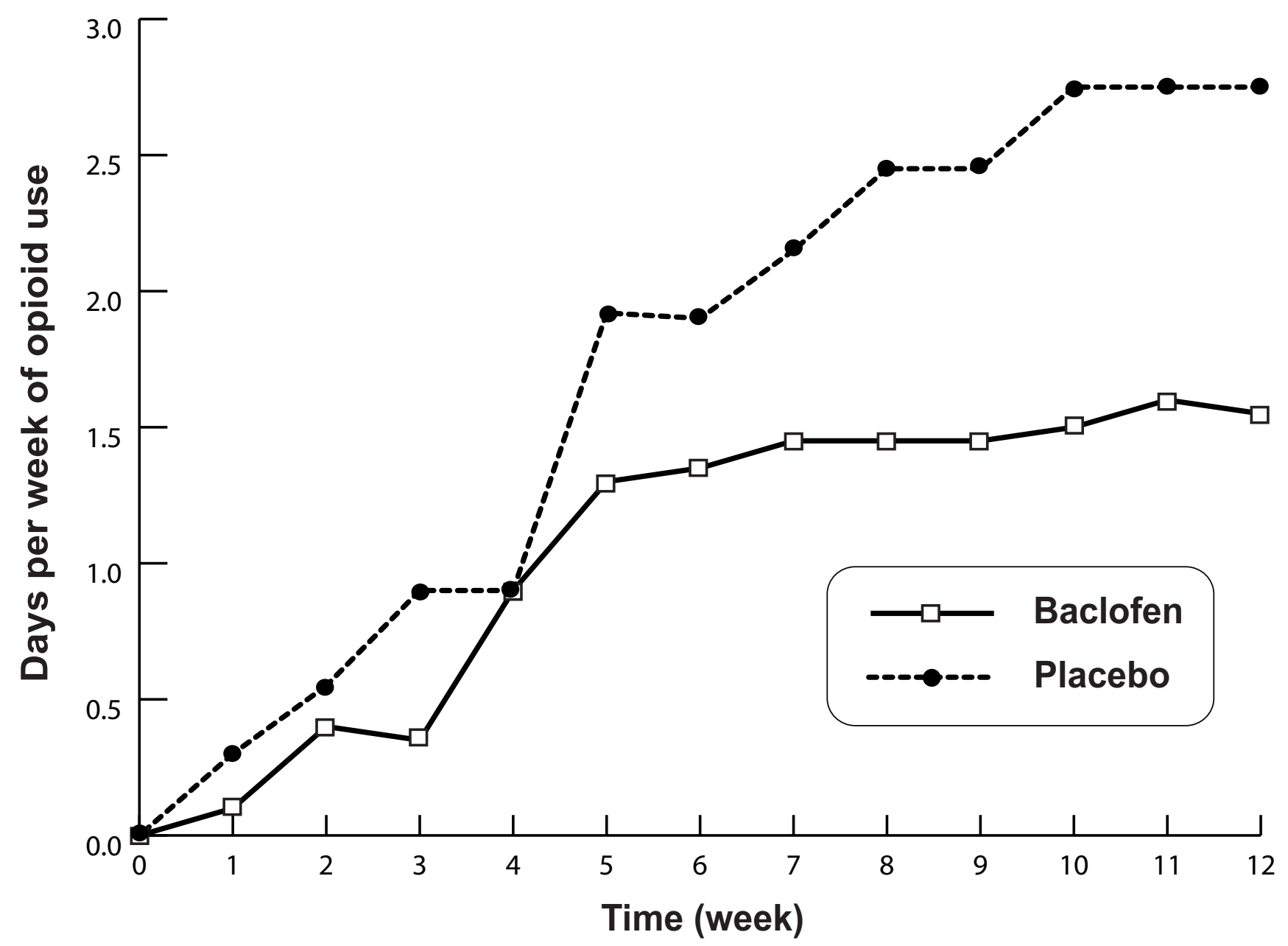

Figure 4

Self-reported days of opioid use per week during the 12 weeks of maintenance treatment with baclofen and placebo.

any significant difference in these measures may be due to the small sample size; for example, there was limited statistical power to detect a difference among the treatment groups on the VAS scores (observed power $=0.21$ ), the self-reported opioid use (observed power $=0.24$ ) and alcohol use (observed power $=0.06$ ). Furthermore, opioid urinalysis was performed weekly and by means of visual evaluation of TLC. In other words, it was performed less frequently and evaluated by less reliable method compared to other studies (e.g. ref. $[27,33,34])$.

The findings of the present study cannot be readily compared with those of other studies because no previous clinical trials have evaluated the efficacy of baclofen in the maintenance therapy of opioid dependence. Yet, our results are consistent with the findings of previous preclinical studies that support the idea that baclofen may be use- ful in the treatment of opioid dependence [10-12,22]. This study may also give some insights about the baclofen's mechanism of action in the management of opioid dependence. Fewer withdrawal symptoms and lower depression ratings in the baclofen group support the idea that baclofen could reduce negative reinforcing effects of opioids; however, non-significant differences in opioid use and craving failed to provide evidence for the efficacy of baclofen in attenuating opioid-associated positive reinforcement.

Attrition rates in our study were nearly twice the rates reported by studies on methadone and buprenorphine maintenance treatments $[27,33,35,36]$. However, beneficial effects of the maintenance treatments for opioid dependence have commonly been tested in individuals who receive extensive psychological treatment and psy- 


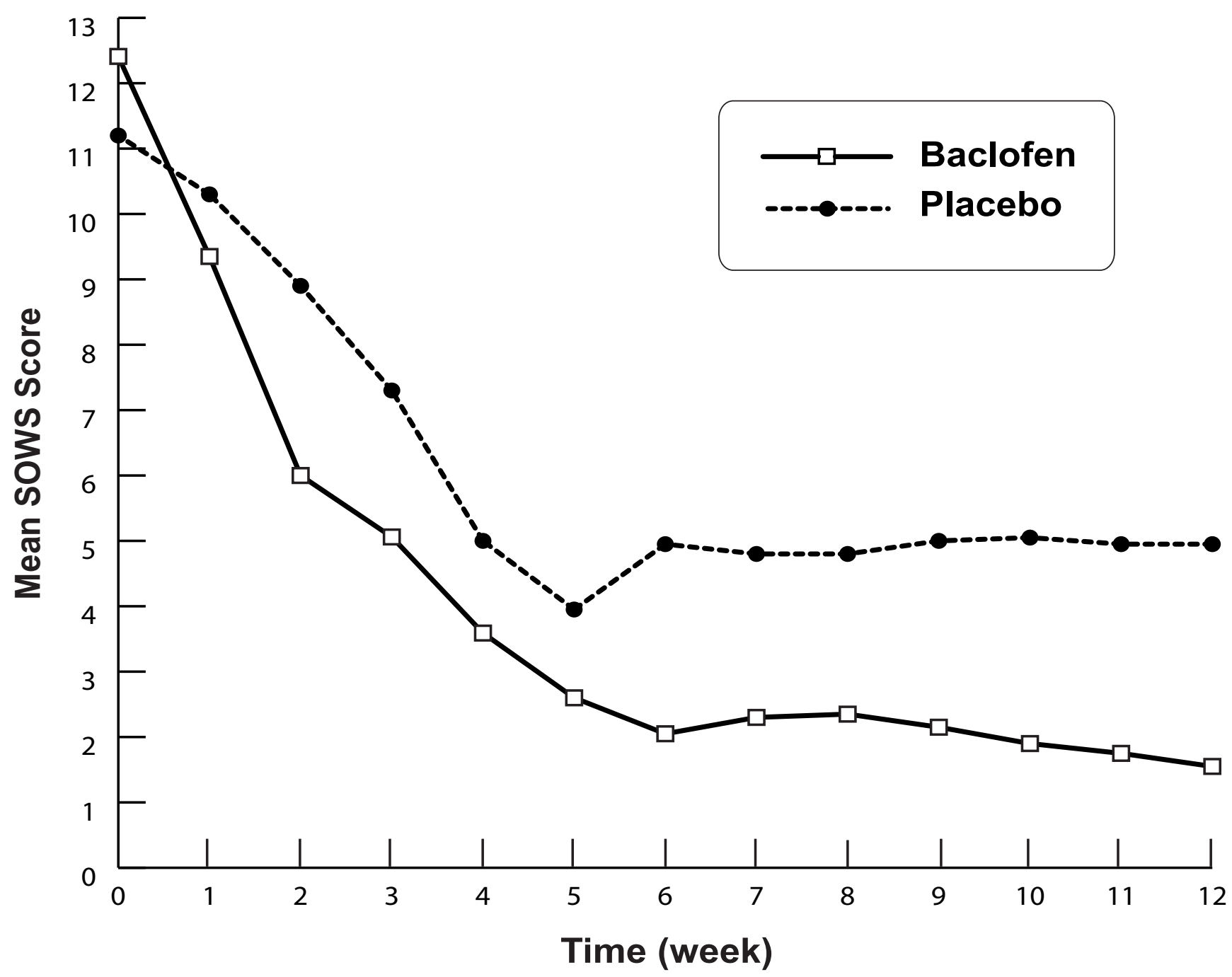

Figure 5

Mean Short Opiate Withdrawal Scale (SOWS) scores during the 12 weeks of maintenance treatment with baclofen and placebo.

chosocial support (e.g. ref. $[27,33,34])$, whereas in our study, subjects did not receive any concomitant psychological treatment or psychosocial support. Interestingly, in a recent study, buprenorphine without any additional support has shown nearly similar retention rates [37].

In addition to the small sample size and limited statistical power on some outcome measures, two other factors limit the interpretation of these data. First, The external validity or generalisability of our findings might be limited by possible differences in patients' characteristics and other local factors. For example, a high prevalence of concomitant cocaine use or dependence seems common in some other countries, but this pattern of codependence is almost non-existent in Iran. Second, the high drop out rate, especially beyond the first half of the trial, threatens the internal validity of the study. Therefore, further studies with larger numbers of patients receiving manual-guided relapse prevention program and psychosocial support are needed to verify the results of this study.

\section{Conclusions}

The results of this study provide evidence to support the hypothesis that baclofen may be of some use in opioid maintenance treatment. However, larger studies are warranted. 


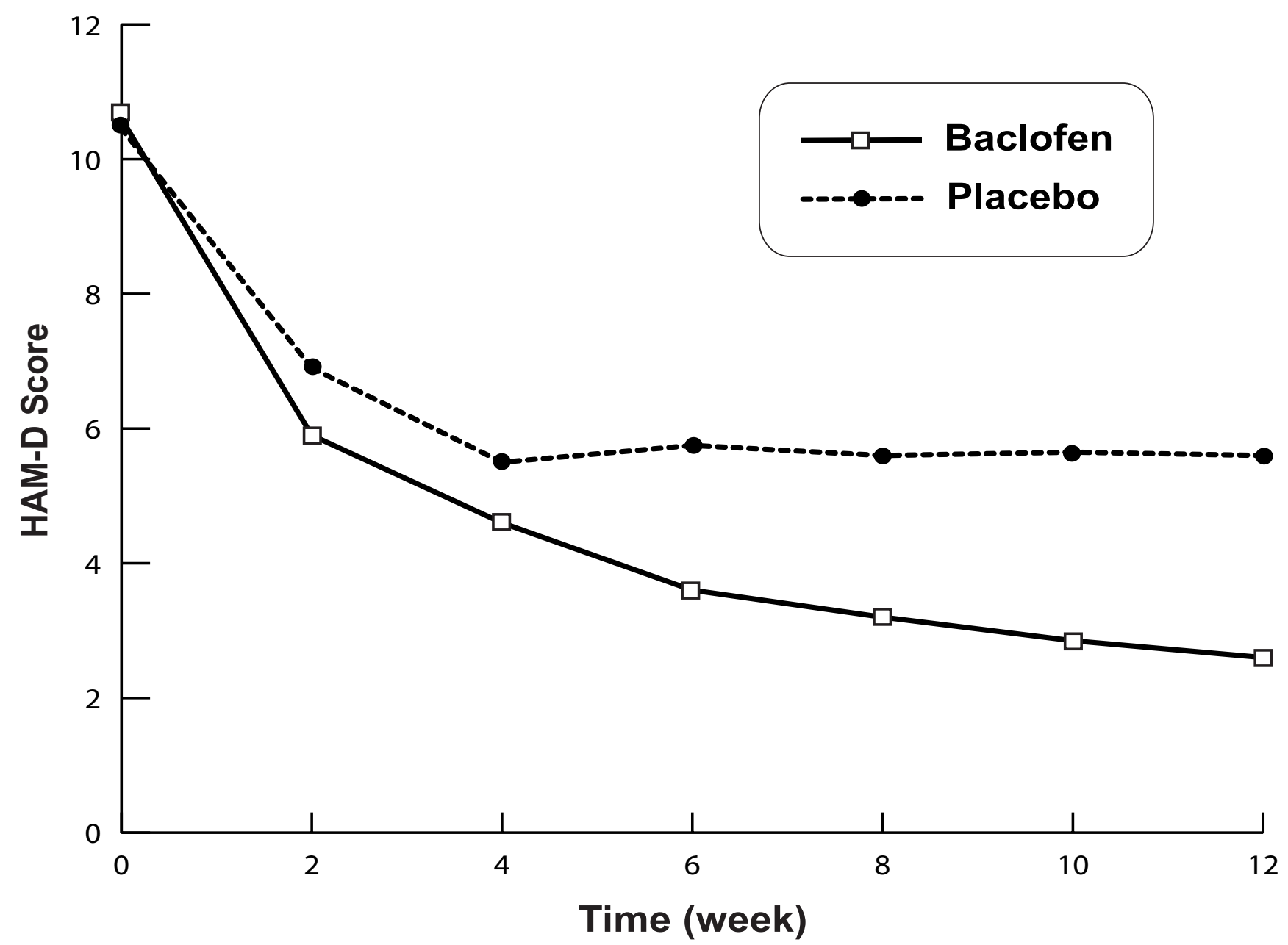

Figure 6

Mean Hamilton Depression Rating Scale (HAM-D) scores during the 12 weeks of maintenance treatment with baclofen and placebo.

\section{Competing interests}

None declared.

\section{Authors' contributions}

SMA conceived of the study, participated in the coordination and design of the study, performed the statistical analysis and wrote the paper (main supervisor). RR carried out the clinical assessment and participated in most parts of the study (main performer). SAA participated in the coordination of the study. All authors read and approved the final manuscript.

\section{Acknowledgements}

This study was Dr. Radgoodarzi's postgraduate thesis and was supported by a grant from Roozbeh Addiction Department (NO. G36). Authors wish to thank Dr. Padideh Ghaeli for invaluable help. This study was presented in part at the fifth annual meeting of the International Society of Addiction Medicine (ISAM), September 2003.

\section{References}

I. Cousins MS, Roberts DC, de Wit H: GABA $\mathbf{A}_{\mathbf{B}}$ receptor agonists for the treatment of drug addiction: a review of recent findings. Drug Alcohol Depend 2002, 65:209-220.

2. Shoaib M, Swanner LS, Beyer CE, Goldberg SR, Schindler CW: The GABA $_{B}$ agonist baclofen modifies cocaine self-administration in rats. Behav Pharmacol 1998, 9:195-206.

3. Campbell UC, Lac ST, Carroll ME: Effects of baclofen on maintenance and reinstatement of intravenous cocaine self-administration in rats. Psychopharmacology (Berl) 1999, 143:209-214.

4. Roberts DC, Andrews MM, Vickers GJ: Baclofen attenuates the reinforcing effects of cocaine in rats. Neuropsychopharmacology 1996, 15:417-423.

5. Brebner K, Phelan R, Roberts DC: Effect of baclofen on cocaine self-administration in rats reinforced under fixed-ratio $I$ and progressive-ratio schedules. Psychopharmacology (Berl) 2000, 148:3|4-32|. 
6. Daoust M, Saligaut C, Lhuintre JP, Moore N, Flipo JL, Boismare F: GABA transmission, but not benzodiazepine receptor stimulation, modulates ethanol intake by rats. Alcohol 1987, 4:469-472.

7. Colombo G, Agabio R, Carai MA, Lobina C, Pani M, Reali R, Addolorato G, Gessa GL: Ability of baclofen in reducing alcohol intake and withdrawal severity: I. Preclinical evidence. Alcohol Clin Exp Res 2000, 24:58-66.

8. Fattore L, Cossu G, Martellotta MC, Fratta W: Baclofen antagonizes intravenous self-administration of nicotine in mice and rats. Alcohol Alcohol 2002, 37:495-498.

9. Ranaldi R, Poeggel K: Baclofen decreases methamphetamine self-administration in rats. Neuroreport 2002, I3: I I07-I I I0.

10. Xi ZX, Stein EA: Baclofen inhibits heroin self-administration behavior and mesolimbic dopamine release. I Pharmacol Exp Ther 1999, 290:1369-1374.

II. Bexis S, Ong J, White J: Attenuation of morphine withdrawal signs by the GABA(B) receptor agonist baclofen. Life Sci 200I, 70:395-401.

12. Zarrindast MR, Mousa-Ahmadi E: Effects of GABAergic system on naloxone-induced jumping in morphine-dependent mice. Eur J Pharmacol 1999, 381:129-133.

13. Wise RA, Newton P, Leeb K, Bumette B, Pocock D, Justice JB Jr: Fluctuations in nucleus accumbens dopamine concentration during intravenous cocaine self-administration in rats. Psychopharmacology (Berl) 1995, I20:10-20.

14. Koob GF, Nestler EJ: The neurobiology of drug addiction. J Neuropsychiatry Clin Neurosci 1997, 9:482-497.

15. Panagis $G$, Kastellakis $A$ : The effects of ventral tegmenta administration of GABA(A), GABA(B), NMDA and AMPA receptor agonists on ventral pallidum self-stimulation. Behav Brain Res 2002, I 3 I: | |5-|23.

16. Willick $M L$, Kokkinidis $L:$ The effects of ventral tegmental administration of GABAA, GABAB and NMDA receptor agonists on medial forebrain bundle self-stimulation. Behav Brain Res 1995, 70:31-36.

17. Lacey MG, Mercuri NB, North RA: On the potassium conductance increase activated by GABA-B and dopamine D-2 receptors in rat substantia nigra neurons. J Physiol 1988, 401:437-453.

18. Ling W, Shoptaw S, Majewska D: Baclofen as a cocaine anti-craving medication: a preliminary clinical study. Neuropsychopharmacology 1998, 18:403-404.

19. Gudeman D, Shoptaw S, Majewska D, Scherf S, Yeats D, Ling W: Preliminary report of baclofen as a cocaine craving medication. NIDA Res Monogr 1996, 174:183.

20. Addolorato G, Caputo F, Capristo E, Colombo G, Gessa GL, Gasbarrini G: Ability of baclofen in reducing alcohol craving and intake: II. Preliminary clinical evidence. Alcohol Clin Exp Res 2000, 24:67-7I.

21. Akhondzadeh S, Ahmadi-Abhari SA, Assadi SM, Shabestari OL, Kashani AR, Farzanehgan ZM: Double-blind randomized controlled trial of baclofen vs. clonidine in the treatment of opiates withdrawal. J Clin Pharm Ther 2000, 25:347-353.

22. Xi ZX, Stein EA: Increased mesolimbic GABA concentration blocks heroin self-administration in the rat. J Pharmacol Exp Ther 2000, 294:613-619.

23. American Psychiatric Association: Diagnostic and Statistical Manual of Mental Disorders Fourthth edition. Washington, DC: American Psychiatric Association; 1994.

24. Del Rio M, Mino A, Perneger TV: Predictors of patient retention in a newly established methadone maintenance treatment programme. Addiction 1997, 92:1353-1360.

25. Saxon AJ, Wells EA, Fleming C, Jackson TR, Calsyn DA: Pre-treatment characteristics, program philosophy and level of ancillary services as predictors of methadone maintenance treatment outcome. Addiction 1996, 91:1 197-1209.

26. McLellan AT, Luborsky L, Woody GE, O'Brien CP, Druley KA: Predicting response to alcohol and drug abuse treatments. Role of psychiatric severity. Arch Gen Psychiatry 1983, 40:620-625.

27. Schottenfeld RS, Pakes JR, Oliveto A, Ziedonis D, Kosten TR: Buprenorphine vs methadone maintenance treatment for concurrent opioid dependence and cocaine abuse. Arch Gen Psychiatry 1997, 54:713-720.

28. Gossop M: The development of short opiate withdrawal scale (SOWS). Addict Behav 1990, 15:487-490.
29. Hamilton M: Development of a rating scale for primary depressive illness. Br J Soc Clin Psychol 1967, 6:278-296.

30. Kaplan EL, Meier P: Nonparametric estimation from incomplete observations. J Am Stat Assoc 1958, 53:457-48I.

31. Mantel N: Evaluation of survival data and two new rank order statistics arising in its consideration. Cancer Chemother Rep 1966, 50:163-170.

32. Mantel N, Haenszel W: Statistical aspects of the analysis of data from retrospective studies of disease. J Natl Cancer Inst 1959, 22:719-748.

33. O'Connor PG, Oliveto AH, Shi JM, Triffleman EG, Carroll KM, Kosten TR, Rounsaville BJ, Pakes JA, Schottenfeld RS: A randomized trial of buprenorphine maintenance for heroin dependence in a primary care clinic for substance users versus a methadone clinic. Am J Med 1998, 105: I00- 105.

34. Stein EC, Bigelow GE, Liebson IA, Stitzer ML: Moderate- vs highdose methadone in the treatment of opioid dependence: a randomized trial. JAMA 1999, 28 I: 1000-1005.

35. Pani PP, Maremmani I, Pirastu R, Tagliamonte A, Gessa GL: Buprenorphine: a controlled clinical trial in the treatment of opioid dependence. Drug Alcohol Depend 2000, 60:39-50.

36. Farré M, Mas A, Torrens M, Moreno V, Cami J: Retention rate and illicit opioid use during methadone maintenance interventions: a meta-analysis. Drug Alcohol Depend 2002, 65:283-290.

37. Krook AL, Brors O, Dahlberg J, Grouff K, Magnus P, Roysamb E, Waal $\mathrm{H}$ : A placebo-controlled study of high dose buprenorphine in opiate dependents waiting for medication-assisted rehabilitation in Oslo, Norway. Addiction 2002, 97:533-542.

38. Addolorato G, Caputo F, Capristo E, Janiri L, Bernardi M, Agabio R, Colombo G, Gessa GL, Gasbarrini G: Rapid suppression of alcohol withdrawal syndrome by baclofen. Am 」 Med 2002, I I 2:226-229

39. Addolorato G, Caputo F, Capristo E, Domenicali M, Bernardi M, Janiri L, Agabio R, Colombo G, Gessa GL, Gasbarrini G: Baclofen efficacy in reducing alcohol craving and intake: a preliminary doubleblind randomized controlled study. Alcohol Alcohol 2002, 37:504-508.

40. Koob GF, Le Moal M: Drug abuse: hedonic homeostatic dysregulation. Science 1997, 287:52-58.

\section{Pre-publication history}

The pre-publication history for this paper can be accessed here:

http://www.biomedcentral.com/1471-244X/3/16/pre pub
Publish with Biomed Central and every scientist can read your work free of charge

"BioMed Central will be the most significant development for disseminating the results of biomedical research in our lifetime. "

Sir Paul Nurse, Cancer Research UK

Your research papers will be:

- available free of charge to the entire biomedical community

- peer reviewed and published immediately upon acceptance

- cited in PubMed and archived on PubMed Central

- yours - you keep the copyright
BioMedcentral 